Original research article

\title{
Conversations about conservation? Using social network analysis to understand energy practices
}

\author{
Jo Hamilton $^{\mathrm{a}, *}$, Bernie Hogan ${ }^{\mathrm{c}}$, Karen Lucas ${ }^{\mathrm{b}}$, Ruth Mayne ${ }^{\mathrm{d}}$ \\ ${ }^{a}$ Department of Geography \& Environmental Science, School of Archaeology, Geography and Environmental Science, University of Reading, PO Box 227, Reading, UK, \\ RG6 $6 A B$ \\ ${ }^{\mathrm{b}}$ Institute for Transport Studies, University of Leeds, Leeds, LS2 9JT \\ ${ }^{c}$ Oxford Internet Institute, University of Oxford, Oxford, OX1 3QY \\ d Oxfam House, John Smith Drive, Oxford OX4 2JY, United Kingdom
}

\section{A R T I C L E I N F O}

\section{Keywords:}

Domestic energy

Energy conversations

Social networks

Low and zero carbon technologies

Low carbon communities

\begin{abstract}
A B S T R A C T
This paper focuses on the use of mixed method social network analysis to understand how people's conversations might influence their energy practices and attitudes to energy conservation. Eighty-five qualitative interviews were conducted with individuals living in six different communities across the United Kingdom. Our analysis sheds new light on who people discuss energy issues with; the social contexts where energy is discussed; and some of the factors that 'open up' or 'close down' energy conversations. We compare the influence of low and zero carbon technologies, and other interventions, on people's energy conversations, and examine how perceived stigmas about discussing energy can be interpreted as 'policing' which can, in turn, inhibit further conversations about energy. We discuss the role that community-based organisations and other non-governmental agencies could play in potentially 'normalising' energy conversations, with the aspiration that such normalisation may influence the adoption of low and zero carbon practices.
\end{abstract}

\section{Introduction}

There is now overwhelming evidence on the need to take action to reduce emissions of $\mathrm{CO}_{2}$ and mitigate climate change [1]. In the UK, and in other high per capita emitting countries such as USA, Australia, Canada and Europe, this requires significant reductions, and changes in energy consumption at the domestic level. However, energy consumption within households is not necessarily perceived as a pragmatic choice. Rather, it is part of a person's personal and social identity, which can be adopted or rejected depending on a number of factors, including their economic, environmental and social concerns [2,3], and subconscious influences. This can be framed in a similar way to the polarisation of perceptions of climate change, i.e. some people feel that concerns over energy consumption are lifestyle choices, rather than about social and environmental justice.

While few people would argue these days that the environment has absolutely no consequence in their daily affairs, only a minority are strongly committed to making significant changes to their household energy practices [4], and conversations about energy and climate change are not commonplace within the UK [5], or in other parts of Europe and the USA [6]. This may, in part, be a symptom of the 'socially constructed silence' around climate change, which is also apparent at national policy scale $[7,8,9]$. In other policy domains, this is often referred to as the 'spiral of silence' [10], whereby a person withholds their opinions on an issue for fear of social isolation. This could also mean that individuals who share similar concerns may never voice their opinions for fear of rejection or stigmatisation [11].

Psychosocial interpretations ${ }^{1}$ of these forms of silence suggest that

\footnotetext{
Abbreviations: EDM, energy display monitor; LZC, low and zero carbon; LCC, low carbon community; LCCC, low carbon communities challenge

* Corresponding author.

E-mail addresses: e.j.hamilton@pgr.reading.ac.uk (J. Hamilton), bernie.hogan@oii.ox.ac.uk (B. Hogan), K.Lucas@leeds.ac.uk (K. Lucas), rmayne1@oxfam.org.uk (R. Mayne).

${ }^{1}$ Psychosocial research perspectives acknowledge that people are psychologically and socially situated. Existing research has revealed a deeper, more complex and

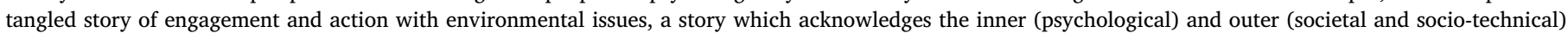

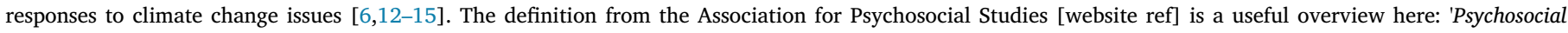

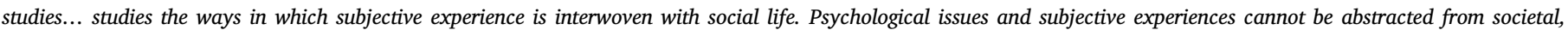

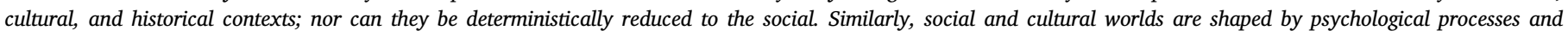
intersubjective relations.' [55]
} 
individuals may prefer to avoid discussing energy and climate change because of the feelings of anxiety, fear, potential loss, guilt and perceived helplessness these issues can evoke $[3,6,12,13,14]$, which can also contribute to 'issue-fatigue' [3]. Such avoidance of anxiety-provoking issues won't make them disappear, but can contribute to different forms of denial, and can cause the anxiety to be split off, projected onto others who have a strong environmental identity [15]. This psychological distancing can contribute to stigmatising people, organisations, and conversations, which attempt to achieve a reduction in energy demand.

In this way, people with a high level of environmental commitment can be pejoratively referred to as 'hippies' or 'tree huggers' by those seeking to distance themselves from environmental debates [16]. Hards [16] further notes that low and zero carbon (LZC) energy practices can be stigmatising, and this can impede adoption when viable. Thus, consideration of what can be done to disrupt these negative associations of energy conservation and the environment, and help to characterize energy conversations as commonplace, could help to broaden the reach and effectiveness of any action resulting from the conversation. This is an important consideration for future domestic energy policy and household's everyday practices and speaks to research questions of the intersection between energy technologies and identities; links between behavioural change and control; various forms of everyday denial [17]; and the relational and social aspects of energy [18,19,20].

Increased conversations and other reflexive approaches could enable people to better process their feelings and emotions around environmentally focused topics $[9,21,22]$. One critical challenge is that, as the impacts of climate change become more pronounced, the scale of decarbonisation required to change the current trajectory becomes more considerable thus appearing increasingly more radical and upsetting for the current status quo and incumbent regimes $[3,15]$.

It is within this wider discourse that our paper explores people's everyday conversations about energy practices and climate change related topics in the UK. It is important to note from the outset that our study is undertaken in places where at least some of our participants are more likely to be thinking about these topics because of their involvement in low and zero carbon (hereafter: LZC) energy interventions within their homes and the community. This will be explained further in the methodology section of the paper.

We pose two overarching research questions. The first is: who do people talk to about their everyday energy practices? For example, do people talk about energy with their close friends only? Do they avoid bringing the topic up with family members for fear of social reprisal? By examining the personal networks of individuals who may be involved in discussing energy practices, we describe how energy and LZC energy topics appear to be relegated to 'close friends', which might reinforce the spiral of silence as individuals appear reluctant to discuss these issues more widely and openly. The second question is: will a LZC energy intervention make a difference to an individual's propensity to discuss low-and zero carbon practices? Our theory is that having an intervention, such as the installation of solar photovoltaic (PV), solar thermal roof panels or better insulation, may act as a 'safe prompt' for individuals to discuss these issues. While our sample selection does not permit a full causal analysis of the intervention, it may still point us towards a greater understanding of what could break this spiral of silence and destigmatise conversations about conservation.

We used a mixed-methods approach to data collection and analysis to explore these issues. Our research is nested within a larger project on low carbon practices. The nature of the data (discussed below) allows us to look at the number of personal network members with whom one discusses energy as well as the qualitative themes that emerged around this topic.

Previous research on energy and climate change conversations has focused more on public opinion, or involved individuals with some commitments to a 'green movement' [23], whereas others argue that social interaction and social networks positively influence weatherization actions in the USA [24], and encourage more personal and interactive communication strategies [3], and increased consideration of the effect of cultural and social contexts in the uptake of LZC practices $[18,19,20]$. Our research builds on these approaches, to focus on a range of individuals within geographical communities in the UK, some of whom self-reportedly did not have an overt commitment to either adopt LZC energy practices or take action on climate change. As the links between climate change and household energy practices are global phenomena, it is essential to identify approaches that are amenable to everyone, not simply those with a green or environmental identity or existing practice. As such, it is critical that we understand how discussions about energy and low-carbon practices occur in everyday life. The findings from this UK context shed light on the importance of the psychosocial context within which conversations about energy occur, which could be useful in other countries, particularly those with high per-capita carbon emissions.

\section{Literature review: everyday topics and everyday networks}

In this paper, we explore under what circumstances individuals will raise energy-related and low carbon issues in their everyday conversations, as well as whom they do this with, and to what effect? Conversations about issues such as energy and climate change are important as they can help develop and maintain a political consciousness around these issues [6,11]; increase appreciation of the associated global challenges [25]; and aid reflexivity [9], which may be linked to the length of the conversation [5].

The uptake of LZC energy practices may benefit from social network effects [3,24,26,27], either through sharing expertise among practitioners and householders (i.e. sharing experiences of LZC interventions), or access to information and verification of the technologies themselves. Additionally, the links between climate, LZC energy and culture at various scales are influenced by local and national narratives and practices [28]. Whilst the links between climate change and LZC energy practices can be different conversational subjects, they are intertwined by local and national narratives, policy responses and practical actions. For example, mitigating climate change through reducing carbon dioxide $\left(\mathrm{CO}_{2}\right)$ emissions, alongside tackling fuel poverty, have been key drivers for energy conservation, efficiency, and renewable energy production projects, at local, national and international levels. Indeed, the Low Carbon Communities Challenge (LCCC) [56], ${ }^{2}$ which this research draws on, was primarily focused around local-scale energy use and $\mathrm{CO}_{2}$ reductions. Nevertheless, linking energy use and $\mathrm{CO}_{2}$ reductions in an uncritical way can be off-putting to some, especially when this does not accord with their identities, values or beliefs $[3,5,26]$. At a national level, it can result in policies which are labelled as 'green' or environmental' being dismissed and marginalised, or discussions shutdown [29]. Thus, we can see that discussion about LZC energy practices are more complex and intertwined than individualistic approaches based on assumptions of 'information deficit' [30] or 'rational actors' [3].

The framing of energy conservation requires connections between multiple organizations, each with a peripheral but necessary interest in energy issues. However, merely linking organizations together is insufficient, as the conversation needs to be facilitated, framed at an appropriate scale [31], and incorporate emotional and spatial connections [28]. It has been suggested that organisations which have the potential to reach across different networks, called 'boundary spanning

\footnotetext{
${ }^{2}$ The Low Carbon Communities Challenge (LCCC) was funded by the then Department of Energy and Climate Change (DECC) in England, Wales and Northern Ireland between 2009-2011. It sought to transform the way communities use and produce energy, and build new ways of supporting more sustainable living Further reports available from: http://www.sciencewise-erc. org.uk/cms/low-carbon-communities-challenge/.[56]
} 
organisations', may help the spread of information across different types of networks [32]. These 'boundary spanning organisations', not constrained by a focus on a single issue/agenda/sector at a specific scale of delivery, can be effective facilitators of energy conversations [31,32]. We can translate boundary spanning in two ways: polysemic contexts (i.e. contexts that can be interpreted in multiple ways, e.g., a children's play that is also about environmental issues) or multiplex relations (i.e. people who are known in more than one context). This has similarities to the 'middle out' concept $[20,33]$, whereby energy conversations and action - could be catalysed and sparked in different contexts.

Given that conversations about energy are potentially loaded with affect and subjective impressions [21] and linked to more emotive issues such as climate change, they are far from neutral. Cultural associations and identities can be triggered, defended against, and projected, which can contribute to stigmatisation. When low-carbon discussions become stigmatised, the speaker has the fear of being labelled or dismissed, and the listener the fear of being judged. What might be considered a mundane conversation about energy bill savings, or the benefits of LZC energy, could be translated into a careful dance of impression management for both the listener and the speaker, as the two avoid trying to judge or to be judged.

\subsection{Social networks}

When taken collectively, the whole of a person's social relationships can be characterized as a personal network, comprising all meaningful interpersonal relationships for any given person. Personal networks are a type of social network where all the network members are connected to a single focal individual, often referred to as 'ego' [34]. For the most superficial and broadest personal network, we might include every passing conversation, or people that the research participant can name through face recognition. More often, however, researchers use a more restricted network based on name recall. This close personal network tends to come from a 'name generator' whereby the respondent lists people elicited with a specific prompt or set of prompts. In this paper, we focus on the people that our research participants regularly discuss important issues with. These 'core network members' are usually used for deliberation and direct support, as well as being a reference group for behaviours and practices [35].

People will talk to each other in varying degrees on a given topic depending on many factors that are pertinent to their relationship with that other person. Some relationships are intense bonds of mutual trust and support, whilst others are instrumentally focused work relationships, or casual friendship acquaintances. Challenges can arise when members of an individual's social network do not align with its social values, or perceived social identity [3]. This can happen when families are split in terms of left and right-wing politics, or on any number of other contentious issues. In these cases, it is not as easy as diffusing information through a network. Instead, the information will only spread to some people, some of the time. It is in this context that we reflect on the role of boundary spanning organisations to assist in introducing topics such as LZC.

\subsection{Stigma within social networks}

Social networks are often described as highly positive forces in an individual's life. It is from networks that we receive both instrumental and affective support. Networks have been shown to be associated with longevity [36], health-related behaviours [37], greater occupational success [38], and increased cultural capital [39]. Putnam's 'Bowling Alone' [40], for example, made a persuasive case that bridging and bonding capital, which emanates from social networks, is responsible for better health, lower crime and overall greater wellbeing outcomes. Much research [e.g. 3,18] and policy [e.g. the Low Carbon Communities Challenge itself, which is what this research focused on] urges the harnessing of social networks to increase uptake of LZC energy practices. However, this positive work on networks tends to play down the complex relational and cultural factors that could impede and disrupt the positive flow of information and practices among networks.

Not all Social Network scholars take a rosy view of interpersonal relationships. Social capital within networks may not be a zero-sum game, but it is certainly not cost free. As Portes and Landolt [41] note, for every person who receives a favour must in turn give a favour. Further, critics of Putnam's [40] positive view of the role of social networks have noted that the American States with the highest social capital also tend to be the most conservative and demographically homogenous.

This issue was explored directly in the case of environmental networks in terms of how people's behaviours can differ through an Ecoteam (an environmentally-minded group) [42]. As well having many positive effects (social support, diffusion of knowledge, etc.), it has been suggested that people's social networks can serve to neglect or omit the unsupportive, detrimental or destructive effects [43]. For example, the Eco-teams study [42] also found that some participants were often left with a feeling that one is not living up to certain expected standards of 'green behaviour'. These are important issues for our own research, because one of its outcome aims is to help to direct future efforts to create sites of 'conversational efficacy' for discussing energy practices with communities [3,5,24,28]. Such contexts should build on, incorporate and enhance the lay knowledge and experience amassed by different community members [27]. The resulting efficacy should enable people to have meaningful conversations about LZC practices without concomitant stigmatising effects.

Given the potentially loaded nature of energy and climate change conversations, we now turn to the concept of stigma, which plays a significant part in the strategic disclosure of topics. As originally defined by Goffman [44], stigma has extended from being a term to describe a religious mark, towards being a general term for types of information that 'contaminate' an individual's identity. Individuals living with a stigma, whether it is a disability, a physical deformity, or a socially unacceptable lifestyle, have their identity preceded by the stigma. That is, they are not fully in control of their impression management as this stigma precedes them, thus are influenced by political and social context of the conversation, as well as the affectual components.

This notion of stigma as a label that precedes identity still persists. Link and Phelan [45] note that components of stigma include: "i) distinguishing and labelling differences, ii) associating human differences with negative attributes; iii) separating 'us' from 'them', and 4) status loss and discrimination" [45:366]. They also remind us to be aware that stigma is a label that is affixed, "leaving the validity of the label open to question" [45:368]. Thus, they support Goffman's assertion of "a language of relationships not attributes" [44:3], and that stigma exists as a matter of degree, which can be challenged by the stigmatised [45]. Hards [16] discusses stigma around energy practices, noting that whilst not as personally detrimental as stigma around disability or race, "theories of stigma can usefully be applied to this under-researched area" [16:441]. We build on this to apply theories of stigma within our analysis, to expand our understanding of its role in the realm of the dissemination and discussion of LZC energy practices. Stigma will not show up here directly in the quantitative analysis of personal networks. It will however emerge in two ways, first in helping us interpret who a respondent chooses not to have a conversation with. Second, it emerges in qualitative interviews that help us understand how conversations happen, and not simply whether they happen.

\section{Methods}

The study upon which this paper is based was part of a wider programme of interdisciplinary action research $[46,47]$. Six 'Low Carbon Communities' ${ }^{3}$ (LCCs), all part of the UK Government funded LCCC, were selected from across the UK to participate in the wider EVALOC ${ }^{4}$ study. Related working papers and reports [48] can be found online 
[57]. The wider project of which this study is one part, held a variety of interventions and engagement activities, though the analysis of the effectiveness of these is outside of the scope of this paper.

Our mixed-methods approach combined a household walk-through survey and interview about household energy practices in response to differing degrees of involvement in Low Carbon Community interventions, a social networks name generator and qualitative interviews about energy conversations between the research participant and their named social networks members. Based on the data that was collected, we quantitatively and qualitatively describe the personal social networks of 85 individuals from six selected case study communities in the UK.

\subsection{Case study communities}

The six LCCs represented a range of socio-economic-demographic and physical characteristics, as well levels of preparedness for changes in energy practices. This is shown in Table 1 .

In common, the LCCs all received funding from the LCCC, but differed in engagement and action strategies, types of intervention and length of time they had been in operation. The EVALOC study recruited around 15 people per community to participate in household interviews. Of these, the first set, group A, (5-6 per LCC) had received technical or behavioural energy interventions through their LCC, ranging from energy generation technologies to energy conservation interventions such as solid wall and loft insulation and double or triple glazed windows. A second set, group B (mainly 5-7 per LCC, one LCC only had 1 in this group) were given Energy Display Monitors (EDMs) and/or some energy related feedback information. A third set who had not been involved in the LCC were recruited through a variety of means (e.g. leafleting at community events, door to door knocking) [48], and simply asked to participate in the household surveys and semi-structured interviews. In some way, this sampling design limits the scope of our conclusions, as there are potential confounding effects in how the sample was recruited. Yet, in all three sets of respondents, there was some modest interest in LCC. Further, those who were part of an intervention and those who simply received an energy display monitor were effectively from the same pool of people as those in group A.

\subsection{Approach to social network analysis (SNA)}

The data for our analysis was collected through detailed face-to-face interviews and social network analysis with 85 individuals, conducted in their home. The content of these interviews was transcribed and analysed in NVivo, first to identify key themes and underlying narratives and then to identify patterns or trends in terms of who talked about what to whom. The composition of the networks was captured through a name generator approach, a standard tool in the social network analysis tradition [49].

This approach commonly involves two or three stages depending on the complexity of the data collection needs. In the first stage, the name generator, the interviewer asks the interviewee to list individuals (referred to technically as 'alters') known via pre-determined criteria; here we elicited names using the 'closeness' of their relationship, i.e. 'who

\footnotetext{
${ }^{3}$ Low Carbon Communities: The organisations in a geographical locality involved in promoting community level energy and carbon reduction. This term can cover a single Low Carbon Community Group or a partnership or multiagency approach involving Low Carbon Community Groups, local authority, other statutory agencies and intermediary organisations.

${ }^{4}$ EVALOC: Evaluating Low-Carbon Communities (EVALOC) research project. EVALOC was designed to assess, explain and communicate the changes in energy use due to community activities within six selected Low Carbon Communities, who received funding for specific energy and carbon-reduction projects from the then Department of Energy and Climate Change's (DECC) "Low-Carbon Communities Challenge" (LCCC). Full report: Gupta et al. [48].
}

are you are most emotionally close to?' - hereafter referred to as "alters" [50]. The next step is "name interpreting". In this step, the interviewee is asked to give details about the alters such as how far away they live from the interviewee and their role relationship (e.g., family, friend, neighbour, etc.). A third optional step involves the elicitation of friendships or relationships between the alters. This step is widely regarded as the most complex step and not always necessary [34] even if it creates 'nice looking' sociograms.

The research team did not include alter-alter ties in the research design as means for capturing them were deemed too complex for this research design (as the network interview was a small portion and we did not restrict the number of names mentioned). This means that any graphics of these networks would look like unremarkable star diagrams with ego (i.e. the respondent) being the only connected to all the alters. Fortunately, the absence of these ties should not inhibit us from employing multilevel modelling [51].

\subsection{Approach to qualitative analysis}

The qualitative interview data was manually coded according to the socio-demographic and household characteristics of the interviewee, their attitudes to the environment and climate change, and whether, or not, they had participated in a conversation about energy with someone in the last month. Emergent codes were also allocated according to the different types of energy conversations people had (e.g. about fuel bill or general energy efficiency issues, etc.), and who they talk to about these issues. The actual content of their conversations under each of these categories was then extracted and qualitatively analysed to explore emergent underlying and arising themes.

Whilst this paper draws on psychosocial and approaches in the interpretation and discussion, this was applied at the analysis stage. That is, the wider research project was not designed from a practice or psychosocial perspective per se, which could limit some of the findings.

\section{Who people talked to: quantitative model results}

85 individuals participated in the social network gathering exercise, which was embedded within an interview and household survey lasting between $1-2 \mathrm{~h}$. We refer to these 85 respondents as egos and the people they nominate as alters.

Of these egos, $72 \%(n=61)$ had some involvement with the Low Carbon Community (LCC). $38 \%(n=33)$ had received a major intervention (described above as variously retrofitting, installation of LZC technology and related work). $33 \%(n=28)$ were involved in a modest intervention such as receiving an energy display monitor or ongoing participation in a learning and action group focused on carbon reduction. Finally, $28 \%$ of egos $(n=24)$ had little or no involvement with the LCC. For our analysis of interventions, these are considered a 'control group'. This group included factors such as being representative of households and dwellings in that community but given that factors such as assignment of LZC interventions had occurred prior to involvement in our research, we recognise that there are some limitations in the comparability of this control group. Additionally, in some LCCs it proved too difficult to recruit participants to Group C [48]. With respect to our outcome variable, 79 of the 85 egos mentioned that they discussed household energy in some context with at least one of their alters. Nevertheless, all 85 are included in our model.

\subsection{The presence of conversations about energy}

Alters were nominated based on whether they were close to the respondent. We then subsequently asked whether they had conversations about LZC. Overall, respondents discussed energy with half of their nominated alters. However, we caution a strong interpretation of this finding. The study took place in the context of a wider government funded LCCC project area (see Table 1), and within interviews that were 


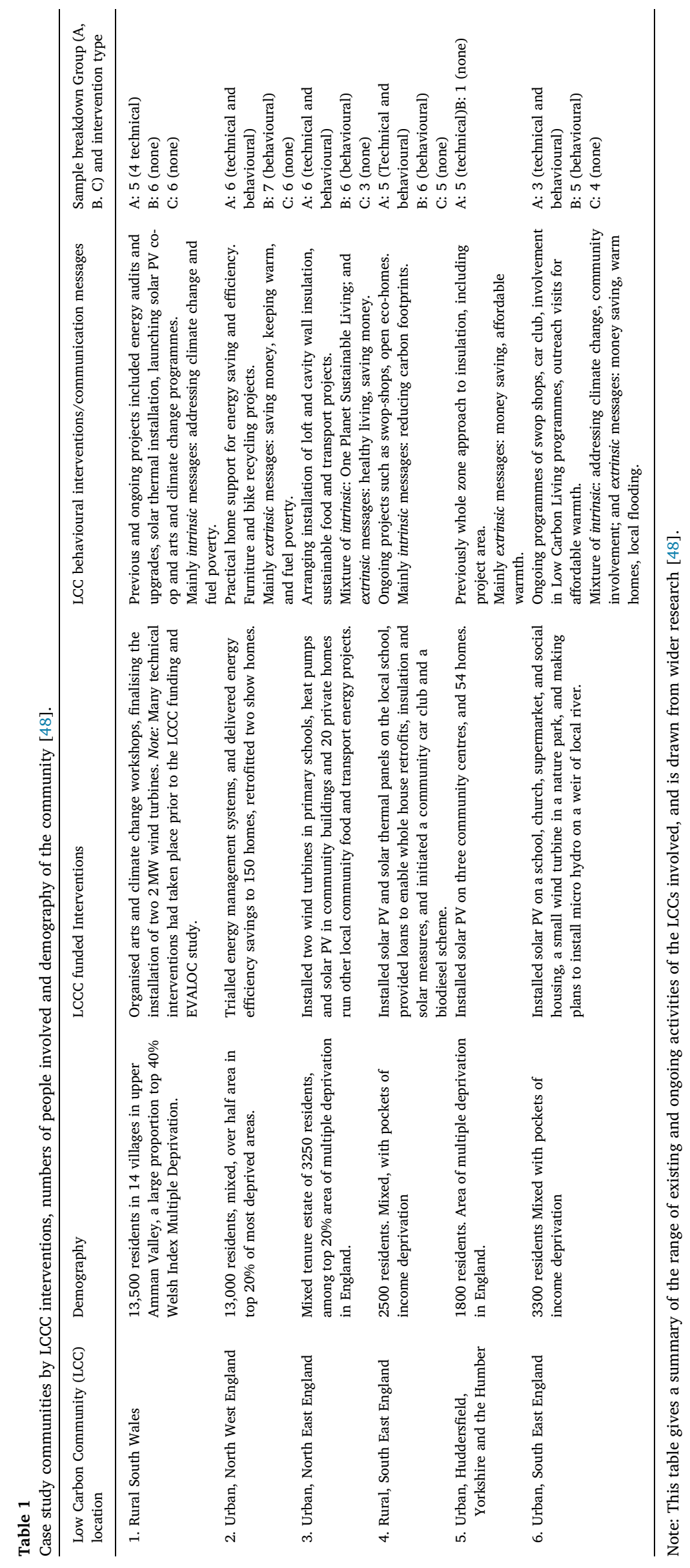



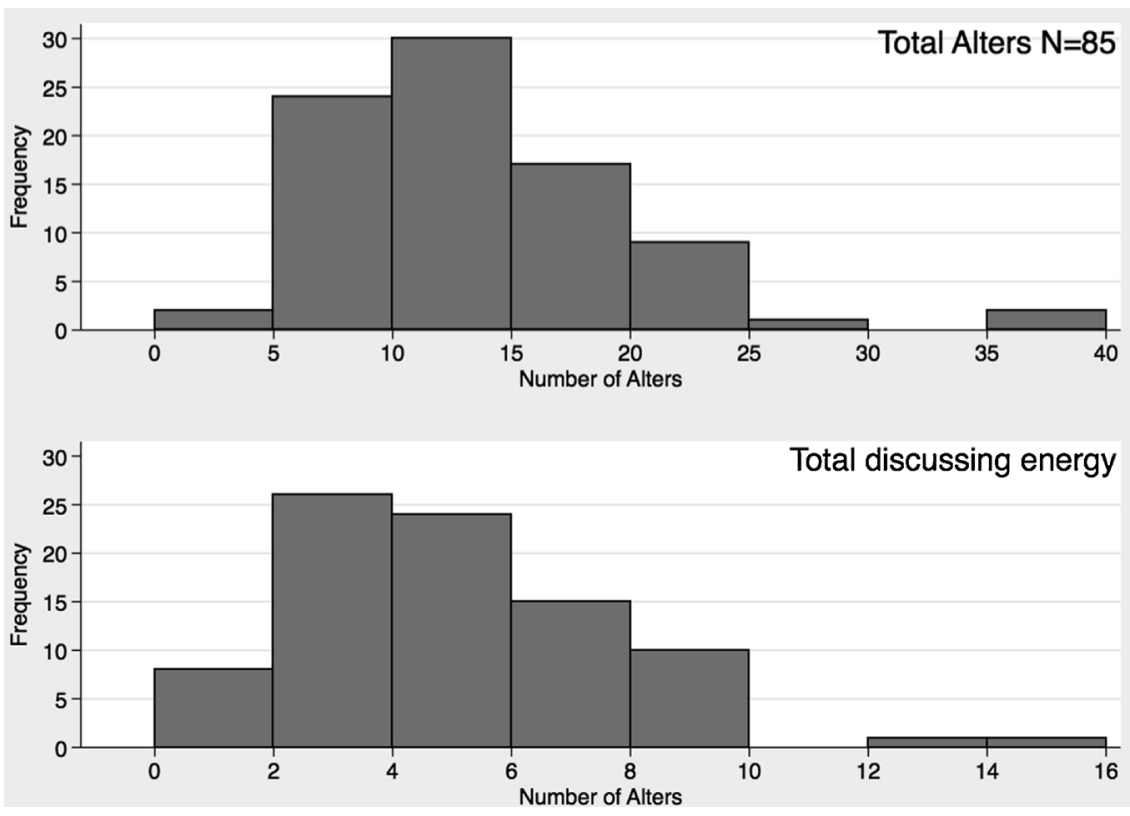

Fig. 1. Distribution of all alters nominated (top) and distribution of alters with whom ego discusses energy (bottom).

specifically about the respondent's energy practices. As such, it is likely that the respondents were predisposed and subject to social desirability effects. This could also help to explain the discrepancy between the number of nominated alters in the sample (13) and the number found in most studies, approximately 25 alters [52]. That is to say, while respondents say they discuss energy with approximately half of their nominated alters, they are likely to have substantially more people in their networks that were not nominated because they do not have energy conversations with them. Nevertheless, even within this context it is worth considering the sort of alters with whom egos discuss energy with.

Fig. 1 shows the distribution of alters compared with those that egos had energy conversations with.

As identified, on average each ego nominated 13.2 alters (with a median of 12). Tests for skewness and kurtosis indicated that this distribution is slightly, but significantly skewed though it is still close to normal (kurtosis is 2.7 where 3 is normal, and skewness is 0.44 where 0 is normal). We are not overly concerned as the distribution is still unimodal with $75 \%$ of egos having alter counts within one standard deviation of the mean. Excluding the two extreme outliers (with alter counts in the $30 \mathrm{~s}$ ) did not change the significance of the models below.

\subsection{The role of alters in the social network}

We asked the respondents to nominate alters by role (such as friend, family, neighbour, etc... as is conventional within SNA studies). This also primes the ego to consider other possible members of the personal network. Table 2 shows that 'family' makes up the bulk of nominated

Table 2

Distribution of alters by role.

\begin{tabular}{|c|c|c|c|c|}
\hline & \multicolumn{2}{|c|}{ Nominated Alters } & \multicolumn{2}{|c|}{ Discuss Energy } \\
\hline & Total & Percent & Total & Percent \\
\hline Family & 5.01 & 0.42 & 2.32 & 0.62 \\
\hline Friends & 4.47 & 0.33 & 1.14 & 0.24 \\
\hline Colleagues & 0.88 & 0.06 & 0.25 & 0.04 \\
\hline Neighbours & 0.94 & 0.06 & 0.19 & 0.04 \\
\hline In LCC & 0.42 & 0.03 & 0.21 & 0.04 \\
\hline Other & 1.34 & 0.10 & 0.19 & 0.03 \\
\hline
\end{tabular}

alters ( $42 \%$ of nominated alters on average), followed by 'friends' ( $33 \%$ on average); that said, family make up almost two thirds of the people with whom ego discusses energy.

Considering the discussion about how energy concerns are partially stigmatized, we expect these conversations to happen among those alters who are closer to ego, both in terms of their emotional relationships and physical proximity. To test this, we move beyond descriptive analysis to a multilevel logistic regression model. Multilevel models are appropriate when the unit of analysis (in this case the dyad of respondent and network member) is nested in a clearly defined hierarchical group (in this case the respondent's network). By accounting for the fact that networks are of differing sizes, people with very large or small networks do not have as much influence on the overall estimation of effects.

The dependent variable is whether or not the ego reported having a conversation with alter about energy. Because each of the egos have their own biases about whether or not to talk about energy as well as a varying number of alters in their personal network, we use a randomeffects multilevel model with only the number of alters varying between ego. This model accounts for the fact that the odds of having a conversation can randomly vary between egos, but alters for any given ego share variance. A preliminary 'variance components model' was used to determine whether there is any variation in the dependent variable between egos [51]. Unsurprisingly, we find significant variation between egos on their propensity to discuss energy with alters. Doing a multilevel model accounts for this shared variance while still giving robust estimates of who in the network ego is most likely to talk to about energy.

Social network studies use multilevel models when individuals are sampled from a population [51]. It is assumed that while many of the alters in any given network might know each other, different people would be nominating different alters. To this extent, we can still treat the respondents as being independent, even if there are dependencies between the alters in any given network. Without specifically articulating the links between alters, we cannot know if ego talks about energy to each alter individually, or to multiple alters at the same time. This is another reason for two features of our model. The first is to use random effects to accommodate the fact that there is shared variance within any network, even if we cannot model all the connections in that network directly. The second is to include role relationships as a covariate. Not only do role relationships help us consider stigma, they also 
Table 3

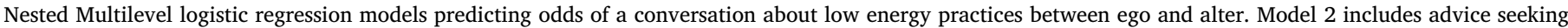
behaviour and model 3 includes the two possible interventions.

\begin{tabular}{|c|c|c|c|c|c|c|}
\hline & \multicolumn{2}{|c|}{ Model 1 Alter features } & \multicolumn{2}{|c|}{ Model 2 Alter interactions } & \multicolumn{2}{|c|}{ Model 3 Interventions } \\
\hline & OR & $\mathrm{p}$ & OR & $\mathrm{p}$ & OR & $\mathrm{p}$ \\
\hline Constant & 0.660 & 0.135 & 0.376 & 0.001 & 0.233 & 0.000 \\
\hline Alter is very close & 3.130 & 0.000 & 2.774 & 0.000 & 2.769 & 0.000 \\
\hline \multicolumn{7}{|c|}{ Alter role type (family is reference) } \\
\hline Friend & 0.393 & 0.000 & 0.384 & 0.000 & 0.390 & 0.000 \\
\hline Colleague & 0.547 & 0.102 & 0.458 & 0.045 & 0.447 & 0.038 \\
\hline Neighbour & 0.177 & 0.000 & 0.167 & 0.000 & 0.160 & 0.000 \\
\hline LCC member & 1.374 & 0.498 & 1.489 & 0.410 & 1.490 & 0.409 \\
\hline Other & 0.290 & 0.021 & 0.271 & 0.023 & 0.267 & 0.022 \\
\hline \multicolumn{7}{|c|}{ Alter's distance (in the community is reference) } \\
\hline In county & 0.354 & 0.000 & 0.382 & 0.001 & 0.390 & 0.001 \\
\hline In UK & 0.263 & 0.000 & 0.297 & 0.000 & 0.293 & 0.000 \\
\hline International & 0.253 & 0.006 & 0.267 & 0.012 & 0.264 & 0.011 \\
\hline \multicolumn{7}{|c|}{ Energy Advice behaviour } \\
\hline Seeks from ego & & & 4.146 & 0.000 & 4.039 & 0.000 \\
\hline Gives to ego & & & 2.393 & 0.000 & 2.437 & 0.000 \\
\hline \multicolumn{7}{|c|}{ Intervention (none is reference) } \\
\hline Modest & & & & & 1.565 & 0.249 \\
\hline Major & & & & & 2.527 & 0.019 \\
\hline \multicolumn{7}{|l|}{ Random effects } \\
\hline Ego & 1.183 & $<0.001$ & 1.219 & $<0.001$ & 1.153 & $<0.001$ \\
\hline \multicolumn{7}{|l|}{ Model fit } \\
\hline$-2 L L$ & -541.17 & & -504.85 & & -502.15 & \\
\hline Wald & 100.16 & $<0.001$ & 137.88 & $<0.001$ & 140.44 & $<0.001$ \\
\hline $\mathrm{N}$ (alters) & 993 & & 993 & & 993 & \\
\hline N (egos) & 85 & & 85 & & 85 & \\
\hline
\end{tabular}

serve as a clear proxy for social connectivity [49,50]. This is because people known by a specific role tend to cluster together.

With multilevel models there is the possibility of clustering at a variety of levels. As we have sampled individuals from six sites, there is the possibility of creating a three-level model that captures dyads nested in networks nested in sites rather than simply dyads nested in networks. However, the inclusion of sites either as an ego-level covariate or as a third level in a multilevel model did not increase the explanatory power of the model. This is not to say there were no differences between the sites, but that these differences were neither statistically significant in distinguishing ego's propensity to discuss LZC with alter nor did they improve the overall model fit. Models were fit using xtmelogit in Stata 13.

We build our model in three stages. The first stage includes attributes about alter from ego's point of view:

(i) Alter's role. We include all six role categories: family, friend, colleague, neighbour, member of the local low-carbon community (LCC) and other. As the largest group, "family" is the reference category.

(ii) Interpersonal closeness. We modelled this as a binary choice of whether or not ego considered alter very socioemotionally close.

(iii) Alter's proximity. We model four categories of proximity: in community, in county, in the United Kingdom and International. "In the geographical community" is the reference group.

In the second model, we included advice-seeking behaviours. That is, did alter come to ego, or did ego go to alter, for advice about energy practices? Our rationale is that the act of seeking advice would be considered a gateway to mentioning LZC practices. To note, this is not always the case. For example, of the 266 alters that went to ego for energy saving advice, 113 (42\%) did not discuss low-carbon/green issues. Similarly of the 229 alters that the various egos went to for advice,
114 (49.8\%) of them did not discuss low carbon with ego. This implies that while there is a relationship between discussing energy saving and low carbon practices, it is not a necessary one. Sometimes those discussions could remain completely practical or money-focused, for example in helping with heating controls or interpreting/comparing energy bills. We discuss this further in the qualitative results.

In the third, and final model we included the two types of interventions. Here we want to know whether the presence of a modest intervention (e.g., an energy display monitor or involvement in an LCC group) or the presence of a major intervention (e.g., energy retrofits and installation of LZC technology) was associated with additional discussions about energy. We asserted earlier that group C, the no intervention group, was a control. However, this is not strictly the case as they were from a more peripheral pool of respondents. To that end, there is a potential confounding of selection effects and causality. That being said, group A and group B were from a similar sample pool. Thus, while we cannot say for certain that the intervention was the causal factor leading to more conversations, if there is a difference between groups A and B relative to group C, this can give us a clue as to whether the major intervention was successful.

Much like a standard logistic regression, we cannot provide a proper $\mathrm{R}$-squared value to suggest the total variance explained. However, we can indicate whether the model is significant. The row for 'random effects: ego' indicates whether the shared variance between egos is significant (i.e. that it is important to model this as dyads nested within alters rather than simply as 993 independent dyads). We can also compare fit across models to assess whether the inclusion of additional variables helps the overall model fit (evinced by the -2 Log Likelihood score, which should decrease with additional variables in the model if the new models are more explanatory). Due to the small sample size we excluded non-significant variables at the standard critical value in social science $(\alpha=0.05)$. To note, we attempted other models with egolevel variables for differences in income, models that included gender 
and gender homophily and both dummy variables. None of these models showed additional significance and are not presented.

\subsection{Multilevel model results}

As we report these 'odds ratios', we want to note that a coefficient of 1 means no difference to the odds of the outcome variable, below one means a reduction in odds and above one means an increase in the odds. Thus, a coefficient of 0.5 means that explanatory variable halves the odds of ego having a conversation about energy with alter and a coefficient of 3 means that such a variable would triple the odds of having a conversation about energy. All models were significant, later models explained more variance (as evinced by the smaller log likelihood scores/high Wald scores) and all included 85 egos and 993 alters (Table 3).

In the first model, differences in alter features make a difference to the odds of having a conversation. These tend to occur in the expected direction. Compared to family members, all groups show lowered odds of having a conversation, with the exception of people from the LCC. Those who are more socio-emotionally close as well as those who are more spatially proximate show greater odds of a conversation.

In the second model, we introduced advice-seeking variables. As expected, both giving advice to alter and receiving advice from alter increase the odds of having a conversation about energy. To note, the effect sizes are quite different. In keeping with our argument about needing permission to speak about low carbon or being reluctant to do so for fear of stigma, it seems ego is more forthcoming when alter seeks out ego. When alter seeks advice from ego the odds of ego discussing energy are multiplied by 4.15 . When ego seeks advice from alter, the odds of ego discussing energy with that alter are multiplied by 2.40 . Indeed, both cases show greater odds of having a conversation than when no advice is sought, but it is when alter comes to ego that the odds are the greatest. Thus, from ego's perspective we can interpret this as ego thinking 'if alter comes to me for advice, I have permission to talk not just about saving money but also about energy saving in general (including the wider issues)'.

Part of this study is meant to examine whether LZC interventions in the community have had an effect on the propensity of ego to discuss energy issues with alter. Model three includes an ego-level variable for an intervention. To note, this is modelled here as a dyadic variable rather than an ego-level variable. We can see that members of group A were the most likely group to have a conversation about energy with their alters. The effect size is strong even if the significance is modest. The association with a modest intervention was more muted. Things such as an energy display monitor might help an individual become aware of their energy use, and have catalysed some conversations, but they do not always constitute a strong enough signal. This is interesting because group A and group B were recruited from a similar pool. Thus, if both groups were more likely than group $C$ to have conversations, we might dismiss this as a selection effect. However, given that there appears to be a significant difference between the control group and A (the major intervention) but not group B (the display monitor), this suggests that the intervention may have been the catalyst for these conversations. While we cannot know for certain given the research design, we believe these findings open up potential for future research designs to more carefully isolate specific interventions as a stimuli to diffuse LZC ideas.

To summarise these quantitative results, egos are most likely to have a conversation about energy with alters who are family, who are nearby and with their strong ties. That is to say, discussing energy appears to be either a 'dinner table' or practical/social support topic rather than one for the pub, the office or the bus station. This is not to say that such conversations are purposefully conducted in private. Rather it suggests that energy conservation and low carbon practices can be loaded topics. Thus, those pursuing strategies to encourage wider participation in discussions about LZC practices could either try to 'de-stigmatise' the topic by focusing on pragmatic concerns such as cost or novelty, and/or use. LZC interventions and associated social learning contexts could provide such a pragmatic context. Alongside careful selection and framing of communication messages, other routes may be to create neutral, shared or polysemic contexts, such as wider community events, where implicit or explicit permission is given to share experiences and know-how about LZC energy practices $[20,28,32,33,53]$. The actual event of doing the intervention might be considered such an event, as people work on their homes or community buildings in the context of considering low carbon practices. Other events might be community plays or bake sales, as some LCCs were already doing (see Table 1).

\section{What people talk about: qualitative results}

In the interviews that followed the name elicitation exercise, we asked respondents about their specific concerns and attitudes towards energy and environmental issues, including climate change. We also asked about their feelings of 'agency' to be able to change their energy practices. We found no significant difference in the number of discussions from those who considered themselves capable of reducing energy in the home, those who were concerned about global warming/climate change or those concerned about energy prices. Many conversations which referenced either major or more modest interventions focused on practicality and novelty. The key arising themes are discussed in the following sections.

\subsection{General energy efficiency}

In total, 47 respondents talked about general energy efficiency, which covered many different aspects of practical advice giving to alters, such as neighbours and friends asking about insulation and other housing retrofits, discussing energy efficient boilers, for example "We talk about boilers and things which are more efficient". Egos also shared novel information based on what they'd learnt from the energy programmes run by the LCC. Compared to discussing energy prices and bills (see 5.2), conversations about energy efficiency didn't seem particularly sensitive, but more about a flow of practical information with appropriate referral to organisations, such as the LCC who offered practical support at the time. The practical aspect of a straightforward and accessible link to action is important to note. This could ease, or even prompt, a conversation about energy, as it can enable agency.

\subsection{Energy prices and bills}

Energy prices and bills were the second most popular area of discussion, with 37 respondents talking about this. This is unsurprising, as some LCC projects were framed around extrinsic messages such as financial savings resulting from energy efficiency practices (see Table 1). In a few cases, some respondents perceived that lack of money was not an issue for some in their social network: "one of the problems here is we live in a very wealthy community and I've got quite a few friends for whom money simply isn't ... a problem". In these cases, using a money-saving frame for discussions about LZC energy may have little impact. This underlines the importance of research focusing on people with high rates of energy consumption too [17].

In households with new low and zero carbon (LZC) technologies, such as solar PV or solar thermal, respondents also discussed whether their panels were making a difference in practical energy saving terms, sometimes in a very light-hearted way, for example: "Just that I got it for nothing and you know so I'm getting me hot water for nowt, you know ... winding them up about it. I think I rang Mick up because he was going off to America on a holiday and I said well I live on a deprived estate Micky, I haven't got that much money but I have got like warm water [laughs]".

Many respondents mentioned the sensitivities about discussing money, which in some cases could imply judgement and stigma, and 
forestall discussion about the potential financial benefits of changing energy practices: "No they think you're going on about money...".

\subsection{LZC technologies and insulation}

The presence of an LZC technology and insulation was an almost equally popular focus for energy conversations as cost savings, with 36 respondents discussing this. These conversations only occurred in specific contexts however, for example respondents might discuss energy within the home such as: "solar panelling, how to save on the bills and things, that's about it" but would not necessarily discuss with friends in some social contexts "If I go out with friends we aren't going to sit and talk about solar panels and things".

For others, whilst energy is discussed within the house, it is also discussed outside the home. This includes social situations such as toddler groups, in other 'normal' situations, in the workplace, or when asked by alters. Some of the conversations focused on the practical or novel aspects of the LZC technology, alongside referring to sources of advice or support, which could help overcome any potential stigma or judgement.

\subsection{Energy display monitors (EDMs)}

The EDMs (some of which were supplied by the LCC as part of their project) appeared to be a catalyst for energy conversations in 10 respondents. For example: "I suppose when they've come down and they've seen it [the EDM] we've just discussed it and I've just said it changes, it just slightly changes the way I use things but that's as far as it goes... I wouldn't preach to them or anything. I think they possibly would [get one] yes". In this way, we can see that whilst there is knowledge of the potential for stigma or judgement in the phrase "I wouldn't preach to them or anything", this is avoided through the EDM being the focus of the communication, not their practices. Additionally, in two LCCs (2 and 6 in Table 1), EDMs were used, reflected on and discussed in a social setting, as an integral part of a learning and action group, which could help 'normalise' conversations in certain contexts.

\subsection{Energy information sharing}

General information about energy was discussed by 17 respondents and fell into two main areas: i) information and discussions about energy through attending an information event, either organised by the LCC, or with a speaker from an LCCs talking, for example a senior citizen's group; and ii) discussions which have been prompted by their involvement in one of the energy saving programs run by the LCC. A person's positioning, either inside or outside the LCC, also influenced their feelings towards talking about LZC energy technologies and practices, and receiving information from others.

The average number of people that respondents consult on energy issues was 2.4 people, with the range between $0-10$. Who the respondent consulted was not restricted to close friends and family, although they featured highly. The individuals who appeared more approachable to discuss energy issues with are those who play a leadership role in the LCC promoting energy schemes, and local authority officers. Respondents felt more comfortable approaching them and discussing the issues with them, even though they might not know them well personally. In general, it seemed that consulting others on energy was very practically focused, and a mostly neutral practice. Whoever the respondents asked, whether friends, family, the LCC or when using the internet, there was a general sense that people could find someone to help them with their queries. This illustrates the importance of people and organisations who can help in polysemic contexts [31], boundary spanning organisations [32], and LCCs who can provide local support.

Sixty-nine respondents mentioned that they were consulted about energy issues in the SNA instrument, but only 44 mentioned these conversations in their interviews. Of these, 23 respondents mentioned that they had positively influenced the energy practices of the alters who they had discussed energy with. This demonstrates the value and potential of positive influence through social networks. In particular, we identified the importance of creating situations whereby knowledge and experience can be shared, and permission given to discuss potentially sensitive or stigmatising issues.

\subsection{Climate change and general environmental issues}

Of the 9 respondents who discussed climate change and general environmental issues, there was no sense that the discussions were 'loaded' or contentious. This seems to be because they were discussing the issues with either members of their family, or people who they considered it was OK to have those discussions with, e.g. "Colin and Helen yes because they're a bit like us, they grow all their veg and they're interested in such matters". Implicit in this quote is the assumption that there are people with whom it is, and isn't, OK to discuss such matters with, and there is a degree of 'impression management' occurring.

These conversations all took place within LCCs who had included wider environmental and climate change framing in their engagement strategies, which suggests that in some cases it was more permissible to discuss such topics.

\section{How we talk about energy: discussion of findings}

One of the key findings to emerge from the in-depth qualitative analysis of people's energy conversations was the role stigma played and the important influence this had on whether, or not, respondents gave or shared their information and knowledge about their energy practices. Although this was not a dominant narrative across all the interviews, exactly how they handled the potential, or shadow, of stigma is insightful for the future planning of community energy campaigns and interventions and creating situations where information and know-how can be shared. It signals the importance of considering how the emotional dimension of conversations, and social networks, influences the dissemination of topics such as LZC energy.

\subsection{Situational contexts}

In total, 23 respondents mentioned situational contexts where they would not discuss energy at all, these include: i) places where people perceived that there were other things to talk about $(n=8)$, e.g. 'we have other things to discuss'; ii) to people who they consider are not really interested, or there's no point in bringing the topic up as they won't change $(n=6)$; iii) to people who they consider are hard to change $(\mathrm{n}=4)$.

It was notable that signs of stigma were not apparent in interviewees from two of the case study communities. This may in part be due to the contrasting framings that the LCC used during the engagement and intervention programme in these areas (see Table 1): one had mostly money saving, extrinsic (and not environmental) messages, the other had focused on more intrinsic messages, such as concern for environment, social justice and community development. Whilst our data is too sparse to suggest a correlation of stigma with certain engagement strategies, it would be valuable to investigate this in future research.

\subsection{Carrying on regardless}

Seven respondents said they were aware of potential resistance to discussing energy from other people but wanted to do it anyway. This can take the form of perceived 'hassling' between close friends, or steering conversations around to the subject of energy in more social settings, for example: "I run a rambling group so ... quite often on the walks ... I will bring the subject round to ... talk about what people are doing to save energy... A bit like preaching [laughs]". In these contexts, it 
appears that there is a certain safety, such as close friends or a cohesive existing group, and that acknowledgement of potential difficulties is treated lightly.

Others were aware that their own interest with energy could be seen to be off-putting, but they persisted in asking and talking about energy anyway: "I phone up to talk to the others... I think they think I'm a bit sort of fixated. The thing is I'll always ask about energy but I'm not asking in a way to say well haven't you thought about such and such I'm just interested to know how much they use [laughs]". However, this same respondent mentioned that he was aware of the potentially judgemental nature of the conversation, that he didn't intend to make people feel awkward, and that he actively tried to make people feel comfortable.

\subsection{Self-censorship}

Six respondents mentioned that they self-censored some energy discussions, both inside or outside the home. Although sometimes mentioned 'half-jokingly', this indicates that some stigma is attached to the topic of low carbon energy practices and discussing money and energy bills. Within the home, it is often associated with the perception of nagging, which could relate to the concepts of domestic sociality [54]. Outside the home it can be perceived as seeming smug or judgemental, for example: "There's one thing that one has to be a bit careful about though and that is appearing to be smug and we don't want to ... you know there is a fine line you walk between trying to promote something and being an evangelist and people getting pissed off with you so we kind of try and walk that fine line". This quote also evidences a keen awareness of the social and cultural contexts within which it is, or isn't, permissible to discuss energy issues, and the associations with which energy may be laden.

Awkwardness about discussing money arose twice in the interviews: "he doesn't feel that comfortable with you know like discussing salaries or this or that because I don't think that is something you should really [discuss with] strangers". In this case it was notable that the 'strangers' were members of the LCC, but not personally known to them as friends, thus there could be some defensive impression management occurring within members of a geographical community.

\subsection{Here come the 'low carbon police'}

An awareness of potential judgement coming from those with a lowcarbon agenda was mentioned by three respondents in different ways. One mentioned a conversation with a neighbour who showed defensiveness about a low carbon agenda, for example:

"I remember his response when he first moved here and he was doing up his house oh you know the low carbon police". In another case, the interviewee describes a neighbour as being "a bit sad" as they were perceived to be obsessed about bills, and friends who "wouldn't want to admit that they were looking at energy changes".

Another respondent was 'on board' with the low carbon message but didn't like the associated 'preaching' from other people: "because much as I like her she's one of those people who just she knows everything and she talks too much and I just can't be doing with it".

These quotes illustrate forms of both stigma, but also psychosocial issues of defences and projection [12], towards individuals and groups who promote environmental action. They also demonstrate a knowledge, not deficit, of information, alongside a surplus of affectual responses, which are not limited to 'rational' responses. This complicates the assumption that early adopters of new practices may be best placed to encourage others [18], or that the power of social networks [3] may always be used to encourage adoption of LZC practices.

\section{Conclusions}

Achieving changes in practices in any sphere of influence is complex due to the interacting range of structural, relational, and individual influences. The quotes and examples illustrate the need to consider psychosocial and non-verbal aspects and cultural contexts of energy conversations: it is not just about what is said, but about what is withheld, and with whom the conversation occurs. We cannot, therefore, expect information, positive experiences and know-how about energy and carbon reductions to automatically diffuse through personal social networks, and influence practices of their friends and families, however well-placed actors may be to do so.

Our research identifies that having an energy intervention is associated with the chances of having a conversation about LZC: people with new energy interventions do discuss their energy practices, and those who are concerned about the environment do raise these issues with members of their personal networks, and can be seen to influence some of them.

However, these interventions need to be considered alongside an appreciation of how energy conversations intersect with both wider conversations about energy and climate change, and inner psychological relationships to issues such as climate change and energy, stigma and identity.

In answering the question 'who do people talk to about their energy practices?', we have noted that our respondents were most likely to have a conversation about energy with those who are family, who are nearby and who are strong ties. Further diffusion of energy messages requires individuals to actively navigate through the attitudes and experiences of those they were talking to and in the situational contexts in which they find themselves. In this paper, we have begun to map the contours of conversational agency and the stigmas associated with energy conversations. With certain individuals, conversations will mainly centre on the novelty of new technology, whilst others will let people know about the potential cost savings. In other situations, speakers may withhold conversations in some contexts for fear of being perceived as either judgmental or the stigma of being labelled as 'an environmentalist'.

We acknowledge a distinct conundrum here. Because of existing stigma about low carbon issues, some environment or climate change focused community organisations may be seen as proponents of the environmental identity we referred to above as 'the low carbon police', regardless of their engagement strategies and range of activities. A defensive reaction may be prompted in their networks, and organisations who may not lead with environmental messaging may still be interpreted as such by people who do not identify as environmentalists.

In answering the question 'will a LZC energy intervention make a difference to an individual's propensity to discuss LZC practices?', we can see that interventions were associated with a difference. As noted above, there are confounding issues with sample selection. This is mitigated by the fact that it was only the major intervention and not the energy display monitor that showed a difference from the control group.

From our analysis of the types of 'listeners and talkers', the nature of conversation itself, the context for these conversations, and the links to taking action, had an influence on how energy interventions and wider energy issues were discussed. As such [and in support of 5,7,26,28,33], policymakers and community organisations need to consider a range of methods for 'framing' energy conversations. It is clear that the spaces and places where conversations can be catalysed or facilitated to enable sharing of experiences with LZC need to be expanded beyond the close, strong ties observed here. This might involve a focus on practicality and 
novelty as well as contexts that create 'safe', or permissible, spaces, which can begin to reframe conservation as an everyday practice rather than as a wholesale identity package. Many of these wider activities were already being carried out by the LCCs involved in this study. This can be assisted by the involvement of, and brokerage by, third parties, such as community organizations and facilitators, local government, NGOs and/or other local agencies. These become the boundary spanning organizations that enable individuals to see the practical benefits of LZC practices, rather than to see it as an identity package that creates impression management challenges.

Enabling the spread of LZC energy know-how, and increasing the agency of individuals and community organisations to act, needs to be considered within the contexts of people's lives and identities. The environment cannot be split from practical concerns about social welfare across class and location and put into a box for 'lifestyle choices'. Our research supports approaches which incorporate boundary spanning organisations and/or polysemic contexts such as a town fairs, congregations or building professionals [33], or approaches which incorporate other forms of participation such as the arts [28]. These approaches appear to be better catalysers and facilitators for conversations and sharing energy know-how than isolated 'environmental awareness' programmes, as the latter implies some form of identity commitment.

Action on carbon and energy reduction needs to be properly resourced, supported and integrated at a local level, and through consistent and long-term policy action at the national and international level. Interventions can work so long as they are sufficiently ambitious to break through stigma, intersect with other issues, and show real results. This is not the time for small steps. Sustained community engagement and practical material changes are needed to successfully catalyse interest in low and zero carbon practices within wider social networks. This research has contributed to the wider interdisciplinary social science conversation about energy through considering what helps, and what hinders, the dissemination and discussion of LZC practices. It has considered the relationship between context, types of intervention, and the role that stigma and other psychosocial influences play in discussing and normalising subjects such as energy.

The research was limited through comparing different LCCs and approaches, and the interview framing of energy and climate change. However, it points to the importance of further research which investigates the role of stigma, and other psychosocial influences, in the transition to a low carbon society. Cross-cultural comparisons of stigma would be an interesting direction for future research, particularly in the current political climates.

\section{Disclosure statement}

No potential conflict of interest was reported by the authors.

\section{Funding}

This work was supported by the Research Councils UK Energy Programme under [grant number RES-628-25-0012].

\section{Acknowledgements}

We would like to thank the reviewers for their critical and constructive comments. We would also like to acknowledge the wider EVALOC project team, and all the LCCs who participated in, and helped, this research.

\section{References}

[1] Intergovernmental Panel on Climate Change/IPCC, Global Warming of 1.5 Degrees, Summary for Policy Makers [online], Available from (2018) (Accessed 12th October 2018), http://report.ipcc.ch/sr15/pdf/sr15_spm_final_pdf.

[2] D. Kahan, E. Peters, M. Wittlin, P. Slovic, L. Larrimore, D. Braman, G. Mandel, The polarizing impact of science literacy and numeracy on perceived climate change risks. Letters, Nat. Clim. Change 2 (October) (2012) 732-735.

[3] P.E. Stoknes, Rethinking climate communications and the "psychological climate paradox, Energy Res. Soc. Sci. 1 (2014) 161-170.

[4] I. Lorenzoni, S. Nicholson-Cole, L. Whitmarsh, Barriers perceived to engaging with climate change among the UK public and their policy implications, Glob. Environ. Change 17 (3) (2007) 445-459.

[5] J. Rowson, A New Agenda on Climate Change. Report [Online], Available from: (2013) (Acccessed 20th November 2016), https://www.thersa.org/discover/ publications-and-articles/reports/a-new-agenda-on-climate-change.

[6] K. Norgaard, Living in Denial: Climate Change, Emotions and Everyday Life, MIT, London, 2011.

[7] A. Corner, J. Clarke, Talking Climate. From Research Practice in Public Engagement, Palgrave Macmillan, Cham, Switzerland, 2017.

[8] A. Corner, Climate silence (and how to break it), Climate Outreach [Online], (2013) Available from http://climateoutreach.org/resources/climate-silence-and-how-tobreak-it/ (Accessed 10th February 2017).

[9] S. Moser, Reflections on climate change communication research and practice in the second decade of the 21 sr century: what more is there to say? WIRES Clim. Change 7 (2016) 545-569.

[10] E. Noelle-Neumann, The spiral of silence a theory of public opinion, J. Commun. 24 (2) (1974) 43-51, https://doi.org/10.1111/j.1460-2466.1974.tb00367.x.

[11] N. Eliasoph, Avoiding Politics: How Americans Produce Apathy in Everyday Life, Cambridge University Press, New York, 1998.

[12] R. Randall, Loss and climate change: the cost of parallel narratives, Ecopsychology 1 (3) (2009).

[13] R. Lertzman, Environmental Melancholia: Psychoanalytic Dimensions of Engagement, Routledge, London, 2015.

[14] S. Weintrobe (Ed.), Engaging With Climate Change Psychoanalytic and Interdisciplinary Perspectives, Routledge, London, 2013.

[15] R. Randall, 'A New climate for psychotherapy?', Psychother. Politics Int. 3 (3) (2005).

[16] S.K. Hards, Status, stigma and energy practices in the home, Local Environ. 18 (2013) 438-454.

[17] B.K. Sovacool, What are we doing here? Analyzing fifteen years of energy scholarship and proposing a social science research agenda, Energy Res. Soc. Sci. 1 (2014) 1-29.

[18] A. Palm, Peer effects in residential solar photovoltaics adoption-a mixed methods study of Swedish users, Energy Res. Soc. Sci. 26 (2017) 1-10.

[19] L. Lutzenhiser, Through the energy efficiency looking glass, Energy Res. Soc. Sci. 1 (2014) 141-151.

[20] M. Moezzi, K.B. Janda, From "if only" to "social potential" in schemes to reduce building energy use, Energy Res. Soc. Sci. 1 (2014) 30-40.

[21] G. Wallenborn, H. Wilhite, Rethinking embodied knowledge and household consumption, Energy Res. Soc. Sci. 1 (2014) 56-64.

[22] M. Büchs, E. Hinton, G. Smith, It helped me sort of face the end of the world': the role of emotions for third sector climate change engagement initiatives, Environ. Values 24 (5) (2015) 621-640.

[23] D.B. Tindall, G. Piggot, Influence of social ties to environmentalists on public climate change perceptions, Nat. Clim. Change 5 (April) (2015) 1-4, https://doi.org/ $10.1038 /$ nclimate2597.

[24] B.G. Southwell, J. Murphy, Weatherization behavior and social context: the influences of factual knowledge and social interaction, Energy Res. Soc. Sci. 2 (2014) $59-65$.

[25] S. Pahl, S. Sheppard, C. Boomsma, C. Groves, Perceptions of time in relation to climate change, WIREs Clim. Change 5 (2014) 375-388.

[26] C. Schelly, Residential solar electricity adoption: what motivates, and what matters? A case study of early adopters, Energy Res. Soc. Sci. 2 (2014) 183-191.

[27] S.J. Darby, Coal fires, steel houses and the man in the moon: local experiences of energy transition, Energy Res. Soc. Sci. 31 (2017) 120-127.

[28] J. Smith, R. Butler, R.J. Day, A.H. Goodbodyd, D.H. Llewellync, M. Rohseb, B.T. Smith, R.A. Tyszczuke, J. Udallf, N.M. Whyteg, Gathering around stories: interdisciplinary experiments in support of energy system transitions, Energy Res. Soc. Sci. 31 (2017) 284-294.

[29] T. McCarthy, Florida Banned State Workers From Using Term 'climate Change' Report, Sunday 8th March 2015 [online]. Available from: The Guardian, 2015 (Accessed 8th January 2017), https://www.theguardian.com/us-news/2015/mar/ 08/florida-banned-terms-climate-change-global-warming.

[30] S. Owens, L. Driffill, How to change attitudes and behaviours in the context of energy, Energy Policy 36 (December (12)) (2008) 4412-4418.

[31] S.E. Kalafatis, M. Lemos, Y.-J. Lo, K.A. Frank, Increasing information usability for climate adaptation: the role of knowledge networks and communities of practice, Glob. Environ. Change 32 (2015) 30-39. 
[32] O. Bodin, B. Crona, The role of social networks in natural resource governance: What relational patterns make a difference? Glob. Environ. Change 19 (2009) 366-374.

[33] Y. Parag, K.B. Janda, More than filler: middle actors and socio-technical change in the energy system from the "middle-out", Energy Res. Soc. Sci. 3 (2014) pp102-112.

[34] B. Hogan, J.R. Melville, G.L. Phillips II, P. Janulis, N. Contractor, B.S. Mustanski, M. Birkett, Evaluating the paper-to-screen translation of participant-aided sociograms with High-risk participants, Proceedings of the $2016 \mathrm{CHI}$ Conference on Human Factors in Computing Systems (2016) 5360-5371, https://doi.org/10. $1145 / 2858036.2858368$.

[35] R. Burt, Network items and the general social survey, Soc. Networks 6 (4) (1984) 293-339.

[36] R.B. Olsen, J. Olsen, F. Gunner-Svensson, B. Waldstrøm, Social networks and longevity: a 14 year follow-up study among elderly in Denmark, Soc. Sci. Med. 33 (10) (1991) 1189-1195.

[37] D. Centola, The spread of behavior in an online social network experiment, Science 329 (2010) 1194-1197.

[38] R.S. Burt, Structural Holes: The Structure of Competition, Harvard University Press, Cambridge, MA, 1992

[39] B.H. Erickson, Culture, class, and connections, Am. J. Sociol. 102 (1) (1996) 217-251.

[40] D. Putnam, Bowling Alone: The Collapse and Revival of American Community, Simon and Schuster, New York, 2000.

[41] A. Portes, P. Landolt, Social capital: promise and pitfalls of its role in development, J. Lat. Am. Stud. 32 (2000) 529-547.

[42] M. Nye, J. Burgess, Promoting Durable Change in Household Waste and Energy Use Behaviour, University of East Anglia, 2008.

[43] A. Clark, Understanding Community: A Review of Networks, Ties and Contacts, Working Paper, NCRM Working Papers Series [online]. Available from: University of Leeds, 2007 (Accessed 12th June 2017), www.real-lifemethods.ac.uk.

[44] E. Goffman, Stigma, Penguin, London, 1963.

[45] B.G. Link, J.C. Phelan, Conceptualizing stigma, Annu. Rev. Sociol. 27 (2001) 363-385.
[46] R. Gupta, L. Barnfield, T. Hipwood, Impacts of community-led energy retrofitting of owner-occupied dwellings, Build. Res. Inf. 42 (4) (2014) 446-461.

[47] K. Lucas, J. Hamilton, R. Mayne, Building capacity through action research: reflections on working with low carbon communities in the United Kingdom, Local Environ. 22 (6) (2017) 725-745, https://doi.org/10.1080/13549839.2016. 1259294.

[48] R. Gupta, N. Eyre, S. Darby, K. Lucas, L. Barnfield, J. Hamilton, R. Mayne, M. Gregg, C. Fratter, B. Irving, Evaluating the Impacts, Effectiveness and Success of Low Carbon Communities on Localised Energy Behaviours (EVALOC). Final Report, Oxford Brookes University and University of Oxford, Oxford, 2015.

[49] B. Wellman, Studying personal communities, in: P. Marsden, N. Lin (Eds.), Social Structure and Network Analysis, Sage, Beverly Hills, CA, 1982, pp. 61-80.

[50] P.V. Marsden, K.E. Campbell, Measuring tie strength, Soc. Forces 63 (2) (1984) 482-499.

[51] M.A.J. van Duijin, J.T. van Busschbach, T.A.B. Snijders, Multilevel analysis of personal networks as dependent variables, Soc. Netw. 21 (2) (1999) 187-209.

[52] B. Hogan, J. Carrasco, B. Wellman, Visualizing personal networks: working with participant-aided sociograms, Field Methods 19 (2) (2007) 116-144.

[53] S. Berry, A. Sharp, J. Hamilton, G. Killip, Inspiring low-energy retrofits: the influence of 'open home' events, Build. Res. Inf. 42 (4) (2014) 422-433.

[54] S. Bell, E. Judson, H. Bulkeley, G. Powells, K.A. Capova, D. Lynch, Sociality and electricity in the United Kingdom: the influence of household dynamics on everyday consumption, Energy Res. Soc. Sci. 9 (2015) 98-106.

\section{Website references}

[55] The Association the Psychosocial Studies [online]. Available from: http://www. psychosocial-studies-association.org/about/. (Accessed 12 June 2018).

[56] Low Carbon Communities Challenge: Further reports available from: http://www. sciencewise-erc.org.uk/cms/low-carbon-communities-challenge/.

[57] EVALOC Research Project: http://www.evaloc.org.uk/. 